\begin{tabular}{ccc}
\hline International Journal of Engineering \& Technology, $7(2.20)(2018) 313-320$ \\
International Journal of Engineering \& Technology \\
Website w ww.sciencepubco.com/index.php/IJET \\
Research paper
\end{tabular}

\title{
Numerical and Experimental Study on RC Exterior Beam-Column Joint with Beam Weak in Flexure
}

\author{
K. Mounica ${ }^{1} *$ and P. Polu Raju ${ }^{2}$ \\ ${ }^{I}$ PG Student, Koneru Lakshmaiah Education Foundation, Guntur-52202. \\ ${ }^{2}$ Associate Professor, Koneru Lakshmaiah Education Foundation, Guntur-52202. \\ *Corresponding author E-mail:mouni.mounicakolanti@gmail.com
}

\begin{abstract}
When the structures are subjected to seismic forces, beam-column joint (BCJ) is the most affected portion of the structure. External BCJs are more vulnerable than interior BCJs. In this present study, both numerical and experimental study has been carried out on external $\mathrm{BCJ}$ to assess the structural behavior. The numerical analysis of the BCJ is done in ANSYS (finite element based) and the experimental study is carried out on loading frame. Three specimens were designed according to IS 456:2000. Out of three, the first specimen was provided with $100 \%$ flexural reinforcement as per design, whereas second and third specimens were reduced with $40 \%$ and $50 \%$ flexural reinforcement as a parameter of beam weak in flexure when compared with the first specimen. The fourth specimen was designed according to IS 13920:2016to achieve the appropriate ductility. All four external BCJs were tested under monotonic tip loading applied on beam and the support conditions are hinged at both ends of the column. These specimens are designed to achieve the strong columnweak beam concept. The deflection, crack pattern and stress intensity are observed and recorded.
\end{abstract}

Keywords: ANSYS, Beam-Column Joint, Beam Weak in Flexure, Ductility, Monotonic Loading.

\section{Introduction}

BCJs are considered as structural members in rigid framed RC structures. It is well known that the beam-column joints are the paramount zones for transfer of loads from beams to columns. When the seismic forces occur the failure happens in joints too because high stresses are produced at the joint portion. So, it is important to take care of the design of the joint to carry more stresses and moments. The design of the joint should be in such a way that beams should fail first when the seismic forces occur. By this design criterion, it satisfies the strong column-weak beam concept and avoids the failure at the joint. In this way, joints can be designed and strengthened. To strengthen the joints, Indian Standards has given a code for the ductile detailing of the joint which is IS13920:2016 [1]. During earthquakes, the connecting beams of a joint are subjected to moments in the same direction either in the clockwise or counterclockwise direction [2]. Therefore, the top bars of the beam move in one direction and the bottom bars move in the opposite direction as shown in Fig 1(a). This causes deformity at the joint as shown in Fig 1(b) and causes major damage to the structure. There are three types of failures in beam-column joints as follows

- Shear failure within the joint.

- Anchorage failure of reinforcement.

- Bond failure of beam reinforcement or column reinforcement which is passing through the joint.

cracking. This diagonal cracking of the joint in the multi-stored structure occurs when the structure subjected to lateral force [5]. The maximum stress occurred in external beam-column joint. The deformation and the stress values are within permissible limits when the joint was analyzed in ANSYS 15 . Here, a G+2 building
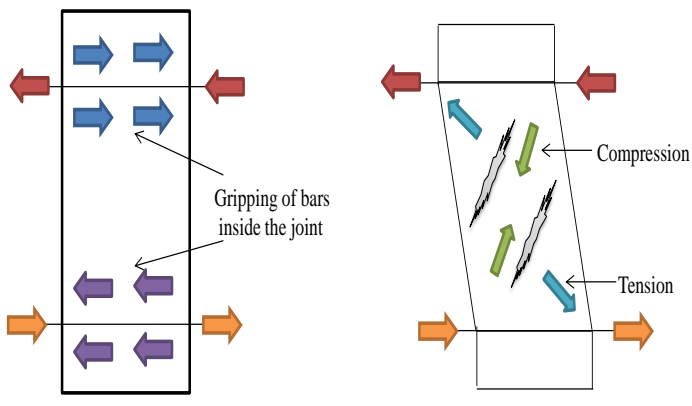

Fig 1: Joint behavior mechanism(i) loss of holding capacityon beam bars in joint region (ii) twist of joint

Under static loading, the RC beam-column with special confinement was done in numerical analysis in ANSYS. The deformation of the specimen having more transverse reinforcement is very less. The maximum shear value is more for the specimen having less transverse reinforcement. Hence the shear strength of the specimens having ductile reinforcement is more [3]. It was concluded that by providing confinement, there was a reduction in damage index. This damage index was flexural dominant element mainly remains the increase of deformation and energy capacity [4]. It was concluded that the joint should be able to carry higher forces than the connecting elements that are beams and columns from the literature study of beam-column joints. The structural behavior of joint in the analysis is different from experimental. When the load applied, the opening of joints occurred and results in diagonal was done in STAAD and modeled in NX CAD. That modeled joint was imported to ANSYS 15 and meshed and analyzed. The results were plotted for shear stress and shear deformation [6]. The analysis of the corner and external beam-column joint in ANSYS was done. Here, many parameters are considered and the results of 
the analysis were plotted. Some of the parameters are maximum principle stress, minimum principle stress, deflection and the displacement of the column with different end conditions like fixed end condition and hinged condition. The stiffness of the joints was also studied. It concluded that the displacement, minimum stress, and maximum stress were increased with increase in load. The displacement, minimum and maximum stress values were less for fixed conditions compared to hinged conditions for both corner and external beam-column joint models [7]. The specimens with special confinement which are designed as per IS 13920 has more energy absorption capacity than the specimens with lateral reinforcement which are designed as per IS 456, SP 34 . With the increase in axial load to the column, there is an increase in stiffness of joint and load carrying capacity. The joint region was free from cracks except for hairline cracks that indicate the joint has adequate shear resisting capacity. All the specimens which are designed as per IS 456, IS 13920, SP 34 are failed due to development of tensile cracks indicating the joint achieves strong columnweak beam concept [8].The ultimate load carrying capacity was $25 \%$ and $38 \%$ higher for the connections with dowel bar and cleat angle than the connections with dowel bar in the positive and negative directions respectively. This was happened due to the additional stiffness and strength developed due to cleat angle [9]. The failure modes of the beam-column connection were classified into four categories namely joint shear failure, slippage of the beam steel, beam flexure and yielding of the column main steel. The beam failure was a flexural failure in case of specimens with joint shear reinforcement while the joint failure was shear failure occurred in case of specimens without joint shear reinforcement The increase of column width in a perpendicular direction on the beam improved the behavior of the beam-column connection [10].

\section{Research Significance}

An extensive investigation was being carried out for many years to know the structural behavior of the $\mathrm{BCJ}$ as it plays a major role in the structural strength. The present study mainly focuses on special confinement to the joint with more ductility. To achieve the strong column-weak beam concept and to happen the failure in beam rather than in joint, the beams are terminated as beams weak in flexure. And also the main criterion is failure should occur in beams rather than in columns.

\section{Experimental Programme}

In all specimens, the dimensions of the beam are $150 \times 200 \mathrm{~mm}$ and the length is $370 \mathrm{~mm}$, the dimensions of the column are $200 \times$ $150 \mathrm{~mm}$ and the length is $1000 \mathrm{~mm}$. The test specimens are designated with "CS", "DS", "BWF-1", and "BWF-2". The CS designated as Conventional Specimen designed as per IS 456:2000 [11] The DS designated as Ductility Specimen designed as per IS 13920:2016 with confined reinforcement. The BWF-1 designated as Beam Weak in Flexure specimen designed as per IS456:2000 with $50 \%$ reduction in flexural reinforcement in the beam, while the BWF-2 designated as Beam Weak in Flexure specimen designed as per IS456:2000 with 40\% reduction in flexural reinforcement in the beam as a parameter. The grade of the concrete is M25 and the grade of the steel is Fe500. As per IS 10262:2009, design mix calculations of M25 grade were made [12]. The materials used were Ordinary Portland Cement (53 Grade), Coarse Aggregate (CA) of size $20 \mathrm{~mm}$ and Fine Aggregate (FA) confirming to zone-II. Target mean strength for M25 grade is $31.6 \mathrm{~N} / \mathrm{mm} 2$ The detailing of the reinforcement provided for a column in the specimens are shown in Table 1 and the detailing of the reinforcement provided for the beam in the specimens are shown in Table 2. The detailing of the specimens was shown in Fig 2 to Fig 5.

Table 1: Detailing of Reinforcement provided in Column

\begin{tabular}{|c|c|c|c|c|c|c|c|c|c|}
\hline \multirow[b]{2}{*}{ Specimen } & \multicolumn{3}{|c|}{ Longitudinal Reinforcement (Top) } & \multicolumn{3}{|c|}{ Longitudinal Reinforcement (Bottom) } & \multicolumn{3}{|c|}{ Transverse Reinforcement } \\
\hline & $\begin{array}{c}\text { Dia } \\
\& \text { Nos }\end{array}$ & $\mathrm{A}_{\mathrm{st}}\left(\mathrm{mm}^{2}\right)$ & $\mathrm{P}_{\mathrm{t}}(\%)$ & $\begin{array}{c}\text { Dia } \\
\text { \& Nos }\end{array}$ & $\mathrm{A}_{\mathrm{st}}\left(\mathrm{mm}^{2}\right)$ & $\mathrm{P}_{\mathrm{t}}(\%)$ & $\begin{array}{c}\text { Dia } \\
\text { \& Nos }\end{array}$ & $\mathrm{A}_{\mathrm{st}}\left(\mathrm{mm}^{2}\right)$ & $\mathrm{P}_{\mathrm{t}}(\%)$ \\
\hline CS & $\begin{array}{l}16 \mathrm{~mm}- \\
3 \mathrm{Nos}\end{array}$ & 603.18 & 0.02 & $\begin{array}{l}10 \mathrm{~mm}- \\
2 \mathrm{Nos}\end{array}$ & 157.08 & 0.005 & $\begin{array}{l}8 \mathrm{~mm}- \\
4 \mathrm{Nos}\end{array}$ & 201.06 & 0.007 \\
\hline DS & $\begin{array}{l}16 \mathrm{~mm}- \\
3 \mathrm{Nos}\end{array}$ & 603.18 & 0.02 & $\begin{array}{l}10 \mathrm{~mm}- \\
2 \mathrm{Nos}\end{array}$ & 157.08 & 0.005 & $\begin{array}{l}8 \mathrm{~mm}- \\
8 \mathrm{Nos}\end{array}$ & 402.12 & 0.013 \\
\hline BWF-1 & $\begin{array}{l}12 \mathrm{~mm}- \\
3 \mathrm{Nos}\end{array}$ & 339.29 & 0.011 & $\begin{array}{l}8 \mathrm{~mm}- \\
2 \mathrm{Nos}\end{array}$ & 100.53 & 0.003 & $\begin{array}{l}8 \mathrm{~mm}- \\
4 \mathrm{Nos}\end{array}$ & 201.06 & 0.007 \\
\hline BWF-2 & $\begin{array}{l}10 \mathrm{~mm}- \\
3 \mathrm{Nos}\end{array}$ & 235.62 & 0.0078 & $\begin{array}{l}8 \mathrm{~mm}- \\
2 \mathrm{Nos}\end{array}$ & 100.53 & 0.003 & $\begin{array}{l}8 \mathrm{~mm}- \\
4 \mathrm{Nos}\end{array}$ & 201.06 & 0.007 \\
\hline
\end{tabular}

Table 2: Detailing of Reinforcement provided in Beam

\begin{tabular}{|c|c|c|c|c|c|c|}
\hline \multirow{2}{*}{ Specimen } & \multicolumn{3}{|c|}{ Longitudinal Reinforcement } & \multicolumn{3}{|c|}{ Transverse Reinforcement } \\
\hline & $\begin{array}{c}\text { Dia } \\
\& \text { Nos }\end{array}$ & $\mathrm{A}_{\mathrm{st}}\left(\mathrm{mm}^{2}\right)$ & $\mathrm{P}_{\mathrm{t}}(\%)$ & $\begin{array}{c}\text { Dia \& } \\
\text { Nos }\end{array}$ & $\mathrm{A}_{\mathrm{st}}\left(\mathrm{mm}^{2}\right)$ & $\mathrm{P}_{\mathrm{t}}(\%)$ \\
\hline CS & $16 \mathrm{~mm}-4 \mathrm{Nos}$ & 804.25 & 0.027 & $8 \mathrm{~mm}-7 \mathrm{Nos}$ & 351.86 & 0.012 \\
\hline DS & $16 \mathrm{~mm}-4 \mathrm{Nos}$ & 804.25 & 0.027 & $8 \mathrm{~mm}-15 \mathrm{Nos}$ & 753.98 & 0.025 \\
\hline BWF-1 & $16 \mathrm{~mm}-4 \mathrm{Nos}$ & 804.25 & 0.027 & $8 \mathrm{~mm}-7 \mathrm{Nos}$ & 351.86 & 0.012 \\
\hline BWF-2 & $16 \mathrm{~mm}-4 \mathrm{Nos}$ & 804.25 & 0.027 & $8 \mathrm{~mm}-7 \mathrm{Nos}$ & 351.86 & 0.012 \\
\hline
\end{tabular}

Hinges are specially fabricated in such a way that the displacement is constrained in $\mathrm{Y}$ and $\mathrm{Z}$ directions and is released in the $\mathrm{X}$ direction. These are fabricated with steel material by welding at required portions and the connections are nut-bolted. The top fin plates are adjustable so that the column dimensions can be variable. The different views of hinges are shown in Fig 6 . The hydraulic jack is connected to the bottom hinge and the whole setup is anchored to the bottom girder as shown in Fig 7. The main purpose of the jack is to apply the axial load to the column. The load on the beam and the axial load on the column through hydraulic jack are applied simultaneously. The experimental test setup is arranged in a way that the column is hinged at both ends and axial load is applied using hydraulic jack with a capacity of 75 Tons on to the column. The linear variable differential transducer (LVDT) is placed linearly below the load cell of the hydraulic jack of loading frame. This is to know the deflection occurred when the load is applied to the beam. It is arranged in such a way that the load cell (capacity of 50 Tons) center is at the tip of the beam. The schematic diagram of set-up and loading arrangement is shown in Fig 8. 


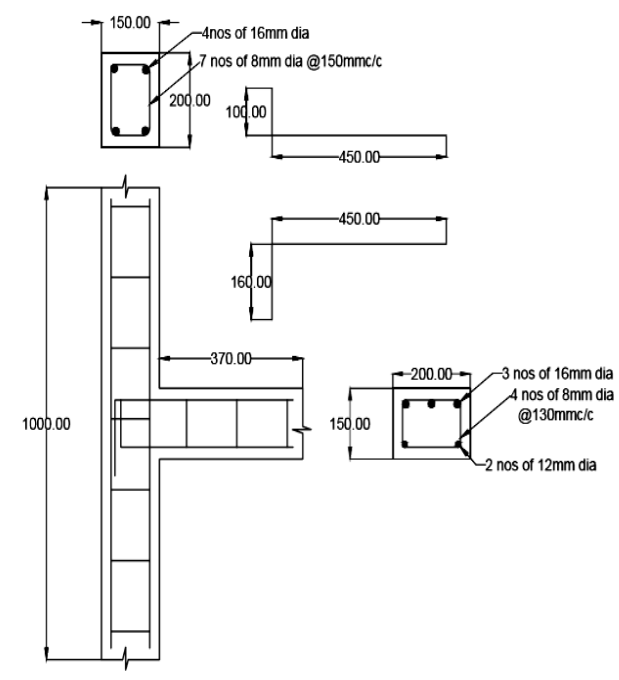

Fig 2: Detailing of CS

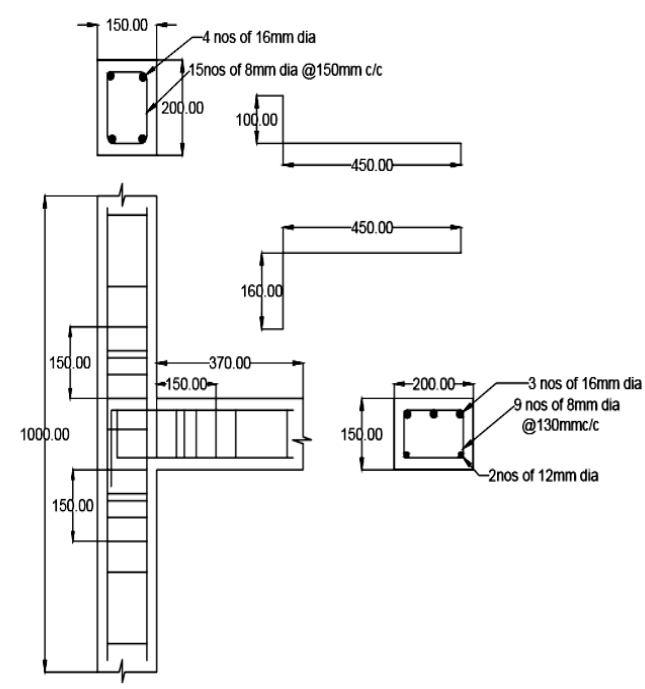

Fig 3: Detailing of DS

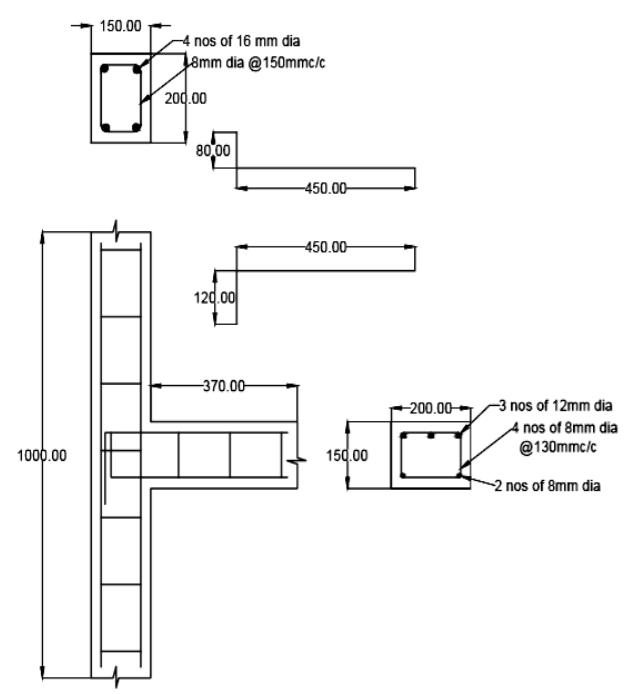

Fig 4: Detailing of BWF-1

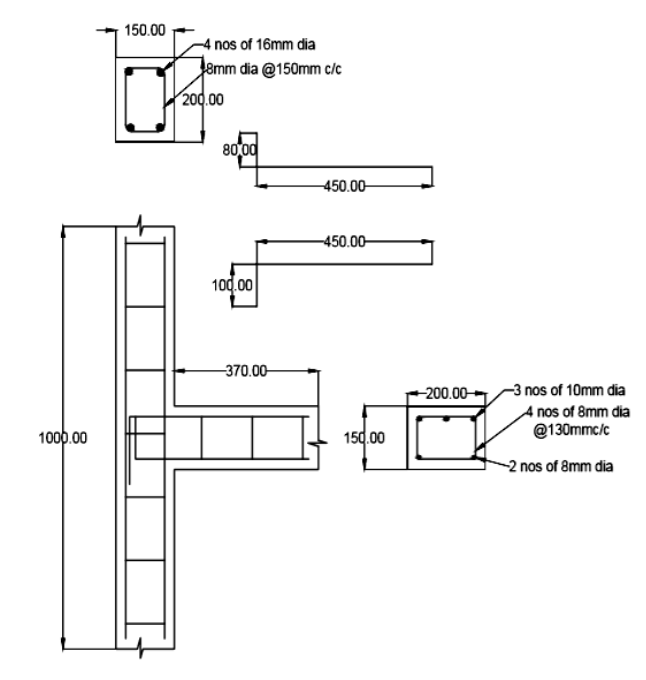

Fig 5: Detailing of BWF-2
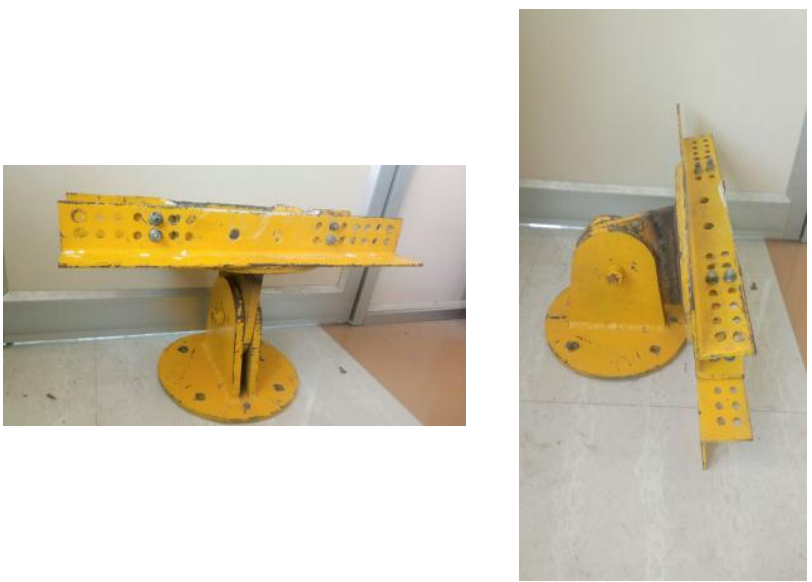

(i) (ii)

Fig 6: Hinges (i) Front View (ii) Side View

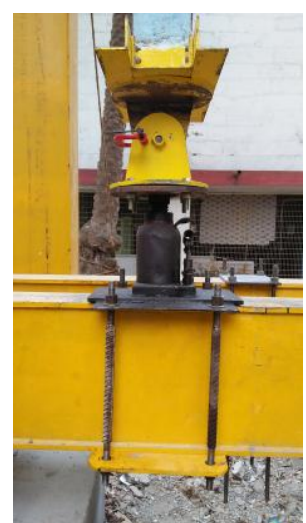

Fig 7: Hydraulic Jack arrangement for the axial load to the column 


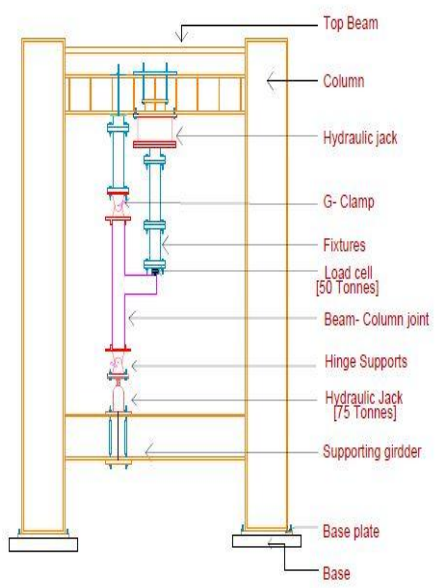

(i)

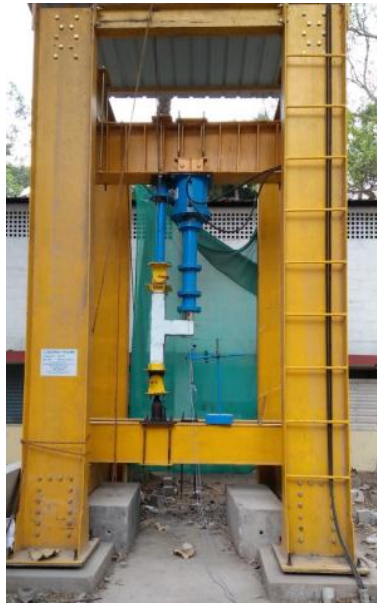

(ii)
Fig 8: Set-up and Loading Arrangement (i) Schematic Diagram (ii) Test set-up

\section{Finite Element Analysis}

Finite element analysis of the BCJ specimens which are tested under monotonic loading was analyzed using ANSYS. The experimental results are compared with numerical results. The concrete element was modeled using SOLID 65 which is an eight-node solid element having three degrees of freedom. It is proficient in handling crushing during compression and cracking during tension. The compressive strength $\left(\mathrm{f}_{\mathrm{ck}}\right)$ of concrete is $25 \mathrm{MPa}$, elastic modulus $\left(\mathrm{E}_{\mathrm{c}}\right)$ is $25000 \mathrm{MPa}$ and the Poisson's ratio $(v)$ is 0.15 respectively. The reinforcement element was modeled using LINK 180 which is a uniaxial tension-compression element having three degrees of freedom. The yield stress of steel $\left(f_{y}\right)$ is $500 \mathrm{MPa}$ and the Poisson's ratio of steel $(v)$ is 0.3 . Since this model is pin jointed, the bending of the element is not considered. The boundary conditions are hinged and are assigned in such a way that the directions $\mathrm{Y}$ and $\mathrm{Z}$ are constrained, and the direction $\mathrm{X}$ is released. These conditions are assigned to the top and bottom of the column. The boundary conditions are allocated based on the experimental setup. The loads applied during the experimental procedure are considered and are applied on tip of the beam by a static method. The axial load of 20 Tons applied to the column for CS\&BWF1\&BWF-2, and 30 Tons for DS. The modeling, meshing, applying boundary conditions to the columns and applying load on beam was shown in Fig 9.

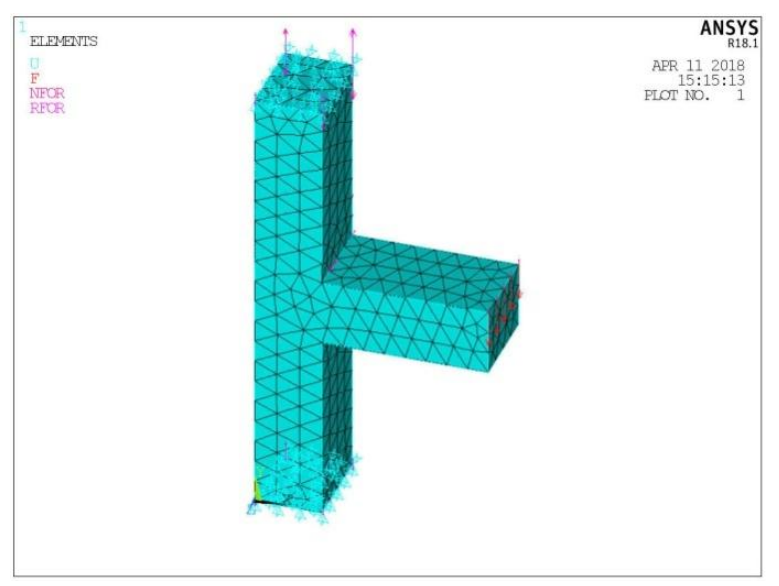

Fig 9: Meshed Model with Boundary Conditions and Loads

\section{Results and Discussions}

The Experimental and Numerical outcomes have been presented and discussed in this section.

\subsection{Experimental Outcomes}

The variation of applied load versus deflection of the beam in all specimens is shown in Fig 10. All specimens are of same concrete but having different reinforcement detailing. The relationship of the load applied versus deflection was in the increasing order of the curve is almost linear for all the specimens subjected to monotonic loading. There is no yielding appearance indication in all specimens. As the peak load was reached, a uniform drop was observed in all specimens indicating the ductile behavior of all specimens under hinge conditions. In Fig 10, the applied load was plotted on the vertical axis and the deflection of the beam was plotted on the horizontal axis. The applied load was set constant. The BCJs are tested under monotonic loading. Applied load is nothing but load applied to the beam which is monotonic. The deflection is zero for all specimens at the initial stage of loading. With the gradual increase of load, the deflection also increased. As expected, the cracks are observed at the joint in all specimens. For $\mathrm{CS}$, the load carrying capacity was $17 \mathrm{kN}$ at $33 \mathrm{~mm}$ deflection. For BWF1, the load carrying capacity was $16 \mathrm{kN}$ at $33 \mathrm{~mm}$ deflection whereas, for BWF2, the load carrying capacity was $16 \mathrm{kN}$ at $32 \mathrm{~mm}$ deflection. And for DS, the load carrying capacity was $26 \mathrm{kN}$ at $33 \mathrm{~mm}$ deflection. From the result data, DS has more load carrying capacity having deflection same as the CS.

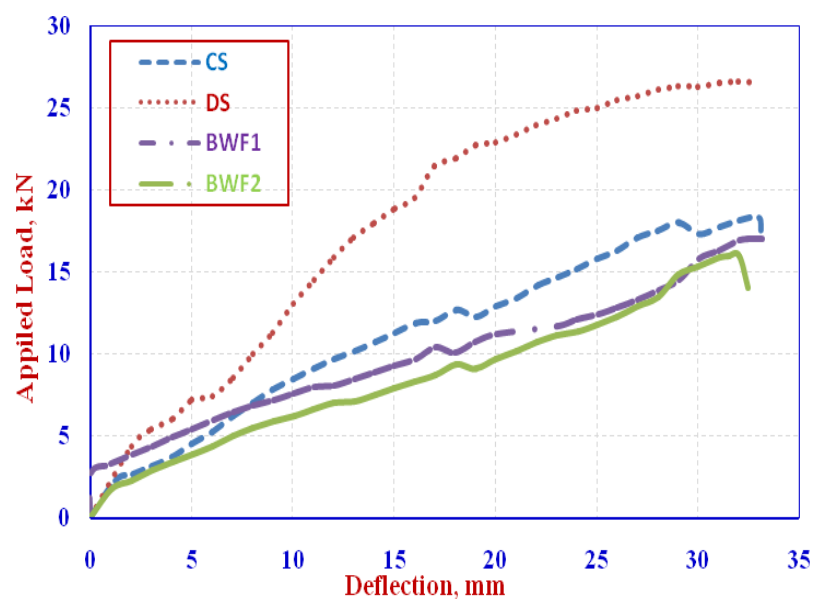

Fig 10: Observed load-deflection curves for all BCJ specimens

The variation of stiffness degradation in all specimens was shown in Fig 11. Stiffness degradation graph was plotted between stiffness and deflection of the beam. Stiffness is defined as it is a measure of the resistance offered by an elastic body to deform. $\mathrm{k}=\frac{F}{\bar{S}}$

where " $\mathrm{k}$ " is stiffness in $\mathrm{kN} / \mathrm{mm}$; " $\mathrm{F}$ " is load applied in $\mathrm{kN} ;$; $\delta$ " is a deflection in $\mathrm{mm}$.

In Fig 11, stiffness was taken on vertical axis and deflection on the horizontal axis. The stiffness of the beam was calculated by considering various peak points of loads and corresponding deflections. The deflection shown on horizontal axis was nothing but the deflection at the stiffness calculated. The stiffness of all specimens is gradually decreased with increased load. The DS was observed with less degradation compared to CS, BWF1, and BWF

2. The stiffness was also high for DS. As BWF1 has less stiffness compared to CS and has high stiffness compared to BWF2, the degradation point for three specimens are same. The stiffness degradation of specimens CS, BWF1 and BWF2 are considerably less than DS specimen and overlapped with each other. This shows the contribution of confinement in joint of specimen DS was significant. Reduction in stiffness indicates shows the damage caused on the joints during loading on the specimens. From graph, the stiffness of DS degrades from $2.3 \mathrm{kN} / \mathrm{mm}$ to $0.9 \mathrm{kN} / \mathrm{mm}$, CS from $1.9 \mathrm{kN} / \mathrm{mm}$ to $0.5 \mathrm{kN} / \mathrm{mm}$, BWF1 from $1.7 \mathrm{kN} / \mathrm{mm}$ to $0.5 \mathrm{kN} / \mathrm{mm}$ and BWF2 from $1.4 \mathrm{kN} / \mathrm{mm}$ to $0.5 \mathrm{kN} / \mathrm{mm}$. Hence, the stiffness degradation was high for DS, it was observed that the curve was 
dropped and raised in between the curve. It concludes that DS has ductility nature with more stiffness.

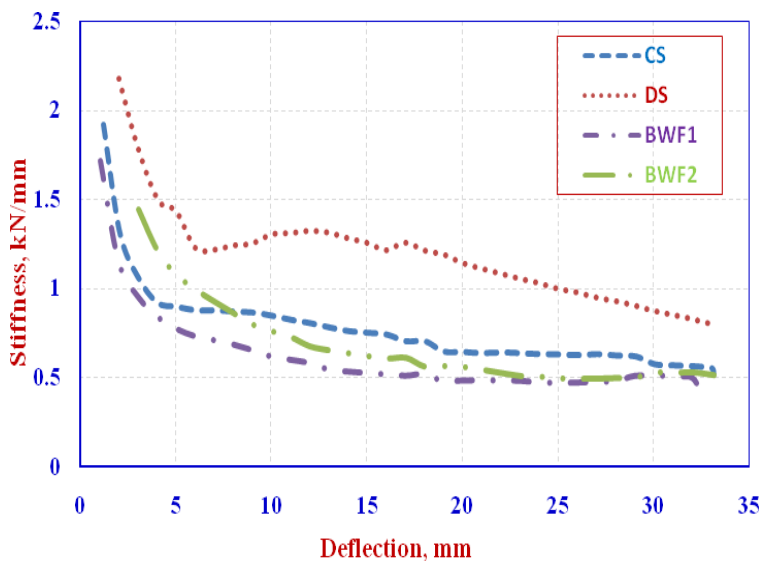

Fig 11: Observed stiffness degradation curves for all BCJ specimens

The variation of shear strength versus drift ratio of all the specimens is shown in Fig 12. It is the normalized graph. Shear strength is defined as the strength of a material against the type of yield where the material fails in shear.

$$
\text { Shear Strength }=\frac{P_{\mathrm{u}}}{\mathrm{f}_{\mathrm{ck}} \mathrm{bd}}
$$

Where " $\mathrm{P}_{\mathrm{u}}$ " is Ultimate load in $\mathrm{N}$; " $\mathrm{f}_{\mathrm{ck}}$ " is the characteristic strength of concrete in $\mathrm{N} / \mathrm{mm}^{2}$; " $\mathrm{b}$ " is the width of beam in $\mathrm{mm}$; "d" is the depth of beam in $\mathrm{mm}$.

Drift ratio is defined as the ratio of maximum drift to a total height of the specimen.

$$
\text { Drift Ratio }=\frac{\Delta}{\mathrm{H}}
$$

Where " $\Delta$ " is the drift of the specimen in $\mathrm{mm}$; " $\mathrm{H}$ " is the height of the specimen in $\mathrm{mm}$.

Here, the specimen was a beam. So, the drift was taken as the deflection of the beam and the height was taken as the length of the beam. In Fig 12, shear strength was taken on the vertical axis and drift ratio was taken on the horizontal axis. Shear strength was calculated from the ultimate load taken from peak points and properties of the specimens. Drift ratio was calculated from the deflections occurred at respective ultimate load peak points. Hence, at initial loading shear strength and drift ratio of the specimens was nearly equal zero. By increase in loading, shear strength gradually increases with increase in drift ratio. The ascending portion of the curve of all the specimens is approximately linear. Compared to CS, DS have more shear strength and BWF1, BWF2 has less shear strength. From the graph, it was clearly observed that the shear strength of DS was increased highly compared to remaining three specimens. Even the remaining three specimens also increased, DS has more shear strength equal to 0.036 where CS has 0.024, BWF1 has 0.023, BWF2 has 0.021 with having almost same drift ratio i.e., 0.09 .

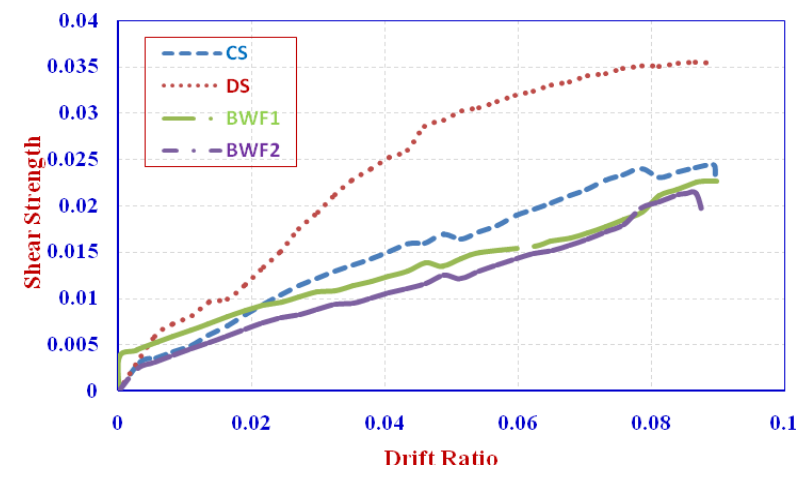

Fig 12: Normalized graph of all BCJ specimens
As expected, cracks occurred at the joint for all specimens. The crack pattern of all specimens was shown in Fig 13. In all specimens, the visible cracks were propagated along the width of the beam from front side to rear side of the specimen. In CS, initially, flexure cracks occurred in the joint. In DS, initially, visible cracks occurred in the joint. Afterward, flexure cracks occurred with an increase in loading on beam and these are propagated towards the top side of the column. And at the point of unloading, the crack close was seen. In BWF1 and BWF2, the cracks are flexural cracks occurred at the joint. The cracks occurred in BWF2 are more than BWF1 as the flexural reinforcement is 10 percent less in BWF2 than BWF1. From results, it was concluded that the DS was ductile in nature and could sustain more loads than other specimens.

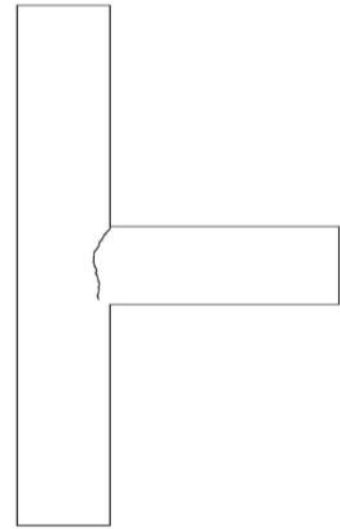

(i)

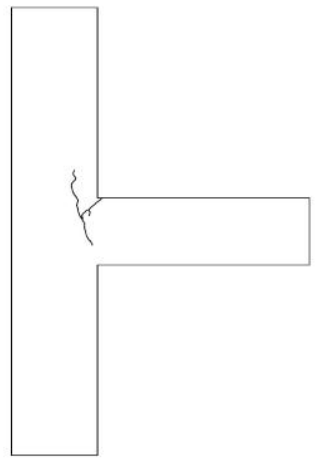

(iii)

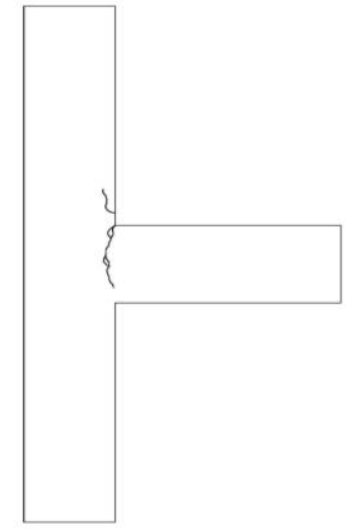

(ii)

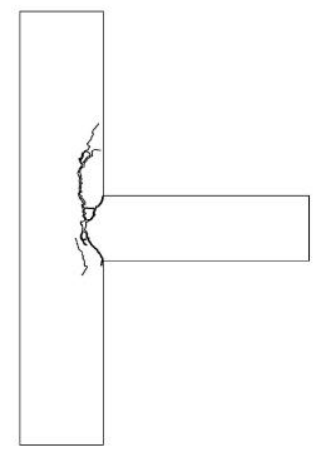

(iv)
Fig 13: Crack Pattern of all BCJ specimens (i) Crack Pattern of CS (ii) Crack Pattern of DS (iii) Crack Pattern of BWF1 (iv) Crack Pattern BWF2

\subsection{Numerical Outcomes}

The deflected shapes of all BCJ models obtained from ANSYS are shown in Fig 14 to Fig 17. Four BCJ specimens were modeled and analyzed namely CS, DS, BWF1 and BWF2 specimen. These are modeled according to the experimental specimens with respective loads. The deflection was more for CS specimen than the three other specimens. In Fig 14 to 17, the deflected shapes of individual specimens were shown. The meshed part shown was the shape of the specimens before deflection and the solid part was the deflected shape. 


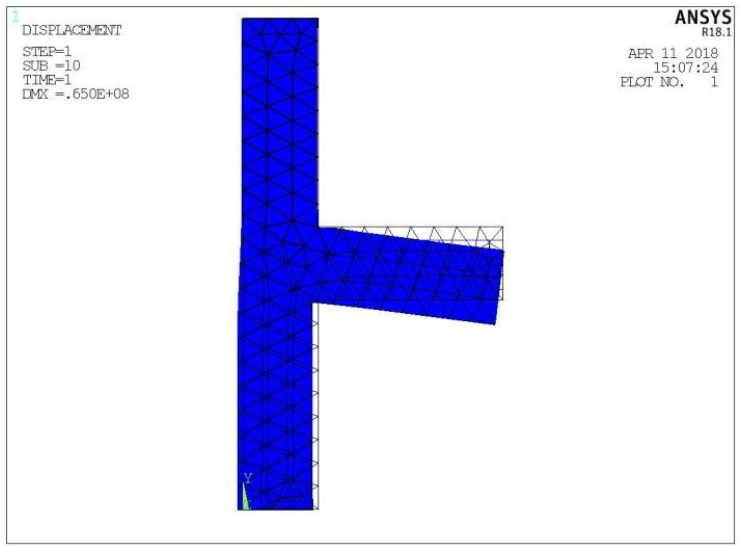

Fig 14: Deflected Shape of CS

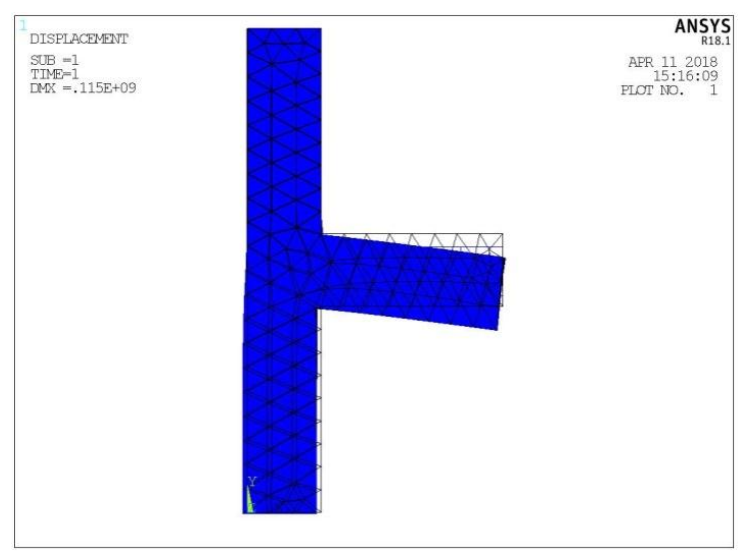

Fig 15: Deflected Shape of DS

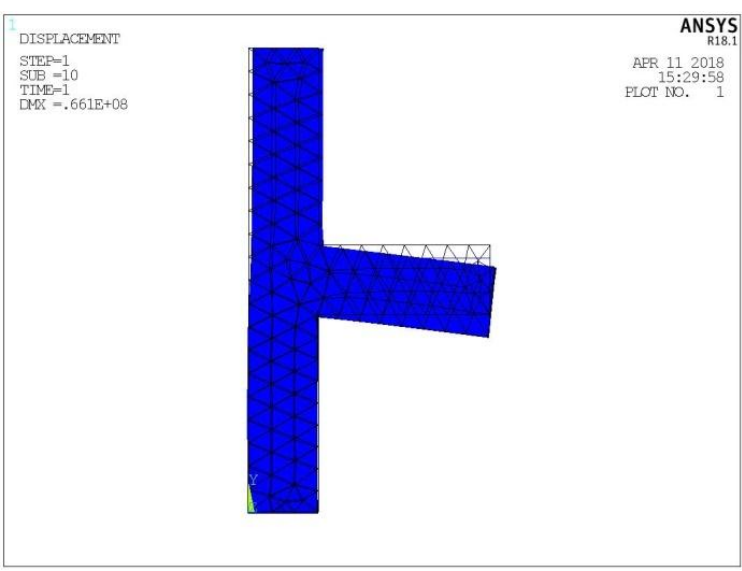

Fig 16: Deflected Shape of BWF-1

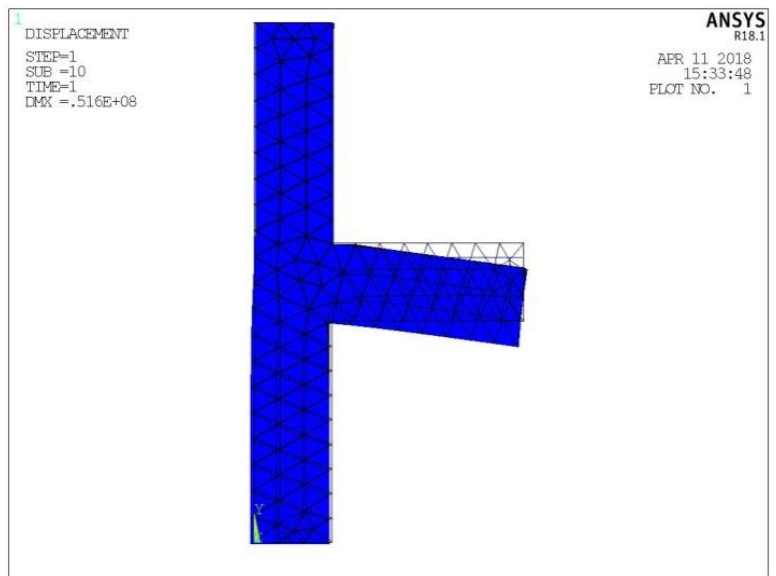

Fig 17: Deflected Shape of BWF-2

The stress intensity of all four BCJ models is shown in Fig 18 to Fig 21. After application of boundary conditions and loads, the resultant stress occurred at the joints. Both maximum and minimum stress occurred at the joint only. CS model has high stress at the joint compared to other three models. DS model has less stress with high loads. BWF1 model has the less value of stress at the joints compared to BWF2 which are lower than the CS model stress value. Due to this high stress at the joint, the failure occurs at the joint only for all models. The red area shown in the figure was maximum stress value and the blue area was minimum stress value.

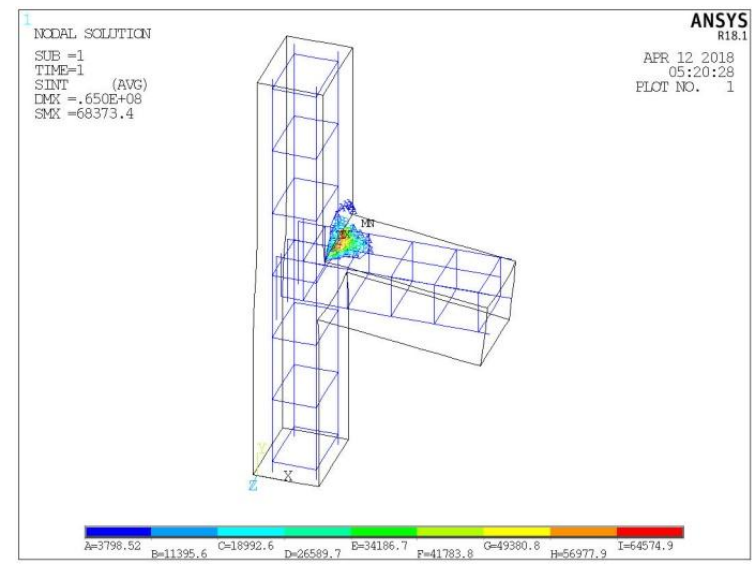

Fig 18: Stress Intensity of CS

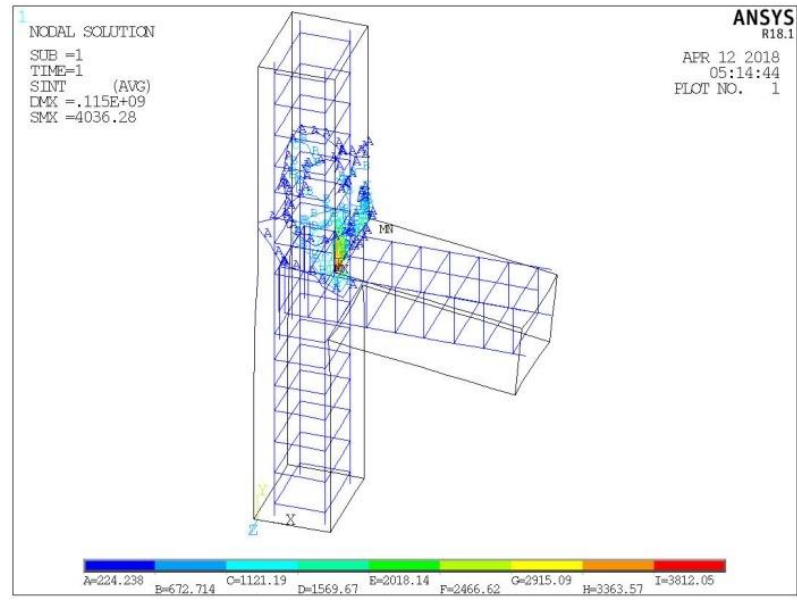

Fig 19: Stress Intensity of DS

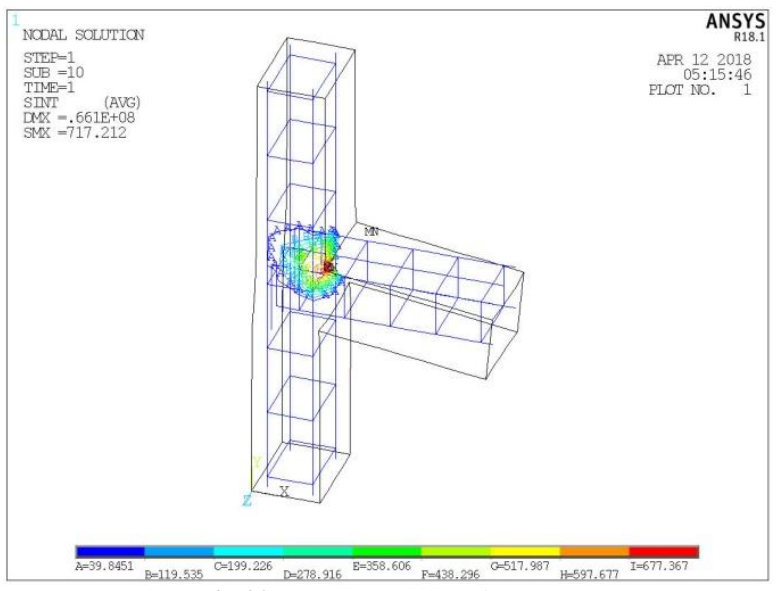

Fig 20: Stress Intensity of BWF-1 


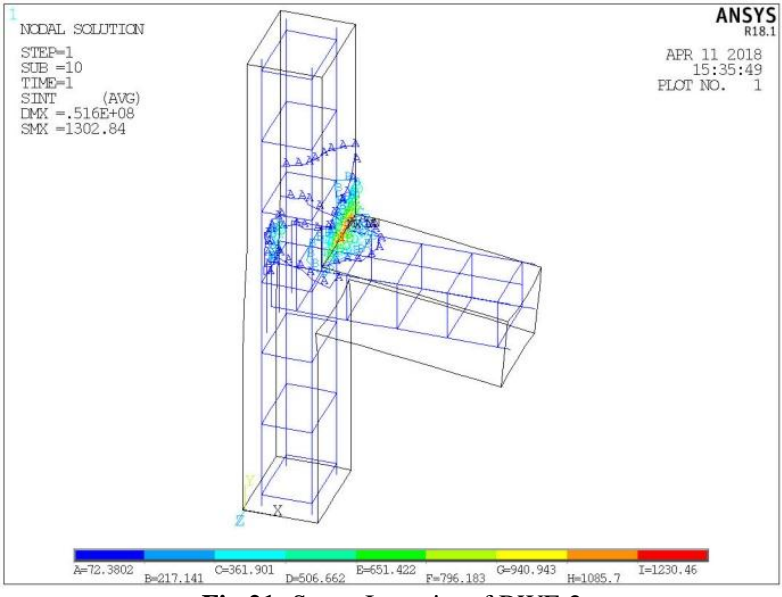

Fig 21: Stress Intensity of BWF-2

Crack Pattern or Crush of the models is shown in Fig 22 to Fig 25. The crushing of the specimen was higher for the DS due to high load application. In both BWF specimens, crushing happens more for BWF1. The CS specimen was also crushed similar to BWF specimens but was lesser than the BWF1 and higher than BWF2. It was also observed that the hinge action appeared in all BCJ specimens. It was clearly shown that all specimens have high stress at column end and beam portions. According to that stress, the cracks and crushing occurred in all BCJ specimens.

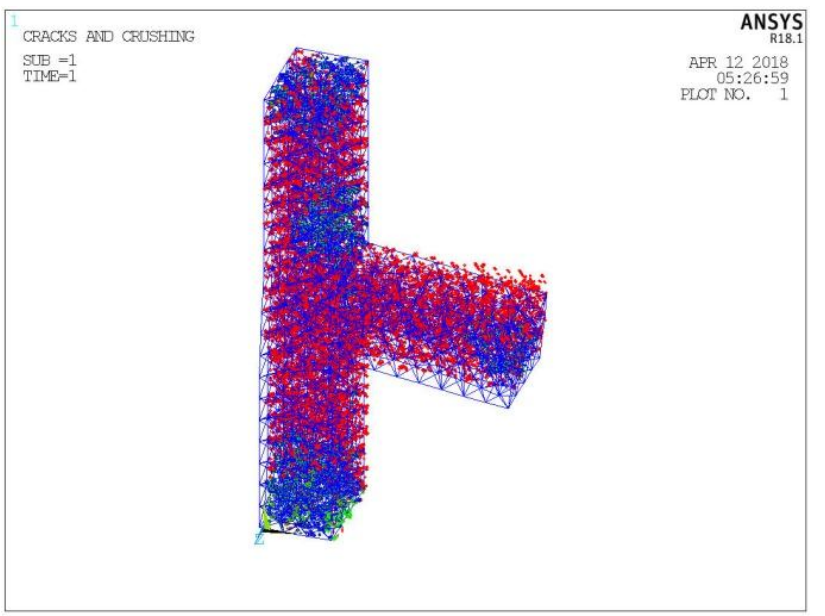

Fig 22: Crack/Crush of CS

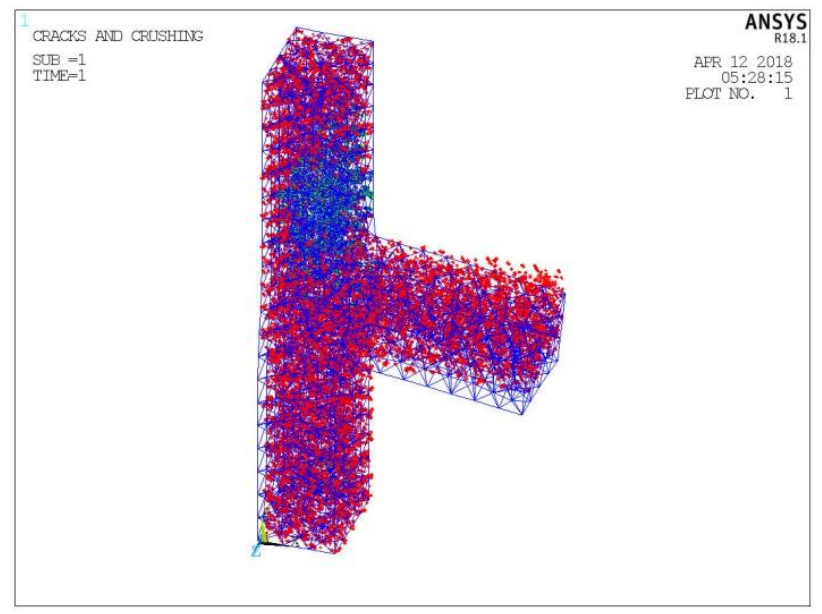

Fig 23: Crack/Crush of DS

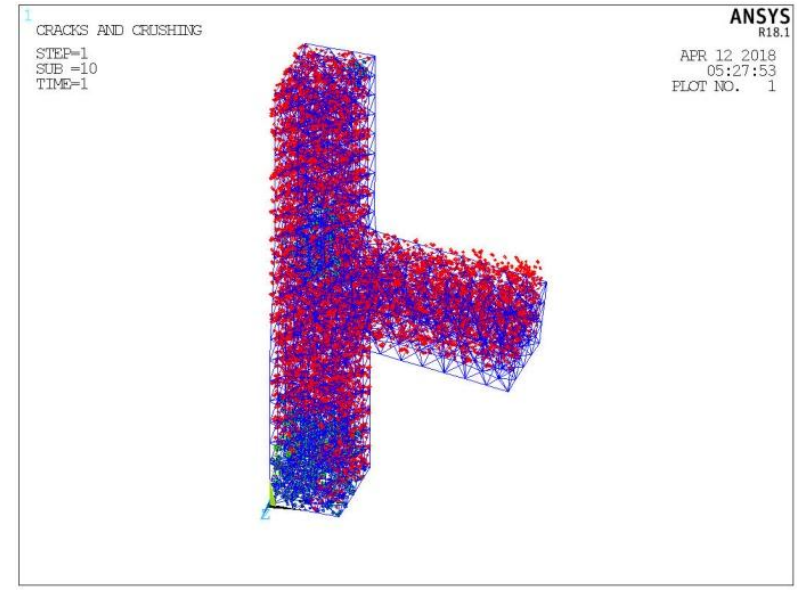

Fig 24: Crack/Crush of BWF-1

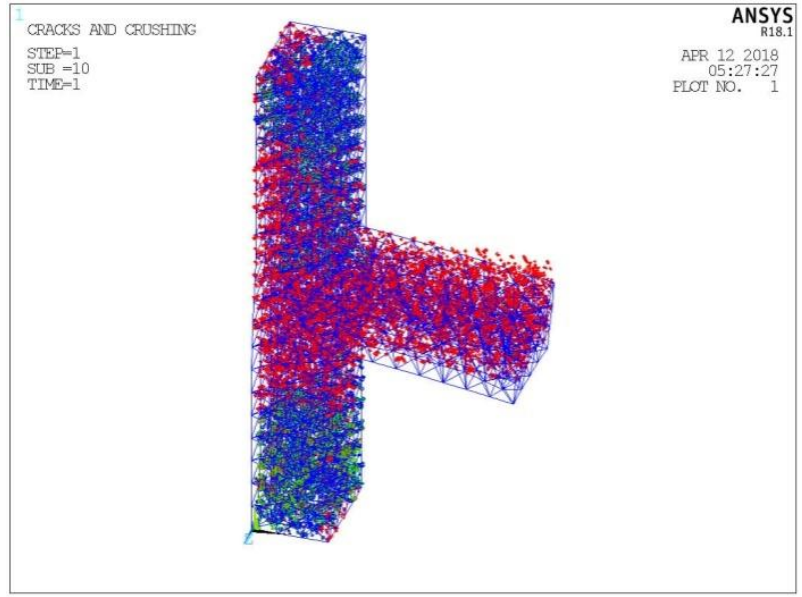

Fig 25: Crack/Crush of BWF-2

\section{Conclusions}

In this present study, the all BCJ specimens behavior has been examined through an immense experimental program under monotonic loading. The test was carried out on beam-column joint specimens with varying reinforcement. The following conclusions have been drawn from the experimental and numerical outcomes.

- All the BCJ specimens fail at the joint under flexure condition. It implies that all specimens achieved the strong column-weak beam concept.

- DS specimen shows more ductile behavior than other three specimens.

- The deflection was same for all the four specimens having different quantities of reinforcement. From this, except the specimen with confinement remaining three specimens deflected significantly with less magnitude of loads. Hence, the load carrying capacity was more for the ductile specimen.

- The stiffness was significant for ductile specimen than the other specimens.

- Stiffness degradation was significant for ductile specimen even though it has high stiffness and load carrying capacity. This is because of the same deflection happened for all specimens.

- The shear strength of the ductile specimen was much significant value than the other three specimens.

- The crack propagation was not significant for the ductile specimen and it has high resistance to heavy loads. The crack propagation was significant for the specimen having nominal flexure reinforcement. It has low resistance to heavy loads compared to the conventional specimen. 
- The DS has shown significant structural behavior while compared with all other specimens in terms of load carrying capacity, shear strength, deflection, and stiffness.

- The maximum stress occurred at the joint of all BCJ specimens in ANSYS, almost similar to experimentally obtained stress. Hence, BCJ specimens failed at the joint in the experiment.

- Even though the flexural reinforcement reduced, the cracks occurred at the joint only.

\section{References}

[1] IS 13920:2016, "Ductile Design and Detailing of Reinforced Concrete Structures Subjected to Seismic ForceCode of Practice" Bureau of Indian standards, New Delhi.

[2] Sneha, A., Hemant, B. and Dahake, B. "Analysis of BeamColumn Joint Subjected to Seismic Lateral Loading", International Research Journal of Engineering and Technology (IRJET), 3(5), pp.346-352, 2016.

[3] Prabhu, N. and Kandasamy, S. "Study on Behaviour of RCC Beam-Column Joint with Special Confinement Subjected to Static Loading Numerical Investigation", International Journal of Innovative Research in Engineering \& Management (IJIREM), 3(1), pp.186-190, 2015.

[4] Abbasnia, R., Mirzadeh, N. and Kildashti, K. "Assessment of axial force effect on improved damage index of confined RC beam-column members", International Journal of Civil Engineering (IJCE), 9(3), pp.238-246, 2011.

[5] Prakash, P. and Dubey, S.K. "Study of Reinforced Concrete Beam-Column Joint", International Journal of Engineering Research (IJER), 4(6), pp.321-324, 2015.

[6] Anusree, L. "Analysis of Exterior Beam-Column Joint Using ANSYS", International Journal of Science and Research (IJSR), 5(7), pp.947-950, 2016.

[7] Patil, S.S. and Manekari, S.S. "Analysis of Reinforced Beam-Column Joint Subjected to Monotonic Loading", International Journal of Engineering and Innovative Technology (IJEIT), 2(10), pp.149-158, 2013.

[8] Bindhu, K.R., Sukumar, P.M. and Jaya, K.P. "Performance of Exterior Beam-Column Joints under Seismic Type", ISET Journal of Earthquake Technology, 46(2), pp.47-64, 2009.

[9] Vidjeapriya, R., Vasanthalakshmi, V. and Jaya, K.P. "Performance of exterior precast concrete beam-column dowel connections under cyclic loading", International Journal of Civil Engineering (IJCE), 12(1), pp.82-94, 2014.

[10] Ahmed G.A., Hassan H.E. and Sabryfayed "Numerical Investigation of RC Exterior Beam Colum Connections under Monotonic Loads", Journal of Mechanical and Civil Engineering, 13(1), pp.60-67, 2016.

[11] IS 456:2000, "Plain and Reinforced Concrete-Code of Practice" Bureau of Indian standards, New Delhi.

[12] IS 10262:2009, "Concrete Mix Proportioning - Guidelines" Bureau of Indian standards, New Delhi.

[13] Subramanian N \& Prakash DS, "Design of Joints in RC Structures with Particular Reference to Seismic Conditions", The Indian Concrete General, (2003). 